\title{
The Shuttle Radar Topography Mission
}

\author{
Tom G. Farr, Mike Kobrick \\ Jet Propulsion Laboratory \\ California Institute of Technology \\ Pasadena, CA 91109 USA
}

On February 22, 2000 Space Shuttle Endeavour landed at Kennedy Space Center, completing the highly successful 11-day flight of the Shuttle Radar Topography Mission (SRTM). Onboard were over 300 high-density tapes containing data for the highest resolution, most complete digital topographic map of Earth ever made. SRTM is a cooperative project between NASA and the National Imagery and Mapping Agency (NIMA) of the U.S. Department of Defense. The mission was designed to use a single-pass radar interferometer to produce a digital elevation model (DEM) of the Earth's land surface between about $60^{\circ}$ north and $56^{\circ}$ south latitude. When completed, the DEM will have $30 \mathrm{~m}$ pixel spacing and about $15 \mathrm{~m}$ vertical accuracy. Two orthorectified image mosaics (one from the ascending passes with illumination from the southeast and one from descending passes with illumination from the southwest) will also be produced.

The technique to acquire this data set has been used for over a decade to produce accurate topographic and topographic change maps (Madsen and Zebker, 1998). Radar interferometry uses the fact that the sensor is phase-coherent, so that if two images are acquired at two slightly different locations, a phase-difference image can be produced that contains information on the topography. The two images can be obtained simultaneously, as with most airborne systems, or at different times, which is the case with all previous spaceborne systems. The main drawbacks to the repeatpass mode is the need to know the baseline separation of the two images to the $\mathrm{mm}$ level, and changes in the atmosphere and surface can occur between the two passes. The baseline can be determined by obtaining a few ground control points, however the other effects are much more difficult to alleviate. Water vapor in the troposphere adds a significant phase delay, which, if different at the two times of image acquisition, will cause large errors in the topographic map produced. This effect has been noted by many investigators; the only feasible way to counteract it is to acquire many pairs of images. Surface changes that degrade the interferometric measurement include incoherent subpixel motion such as the waving of leaves and branches on trees. This decreases the amount of correlation between the two images, increasing the error of the phase measurement. In extreme cases, complete decorrelation results in loss of the phase information.

To avoid the problems with repeat-pass interferometry, SRTM acquired its two images simultaneously. SRTM used the same radar instrument that comprised the Spaceborne Imaging Radar-C/X-band Synthetic Aperture Radar (SIR-C/X-SAR) that flew twice on Space Shuttle Endeavour in 1994 (Evans et al., 1997). SIR-C/X-SAR was a cooperative project between NASA and the German and Italian Space Agencies and obtained data for over 50 science investigations. To collect the interferometric data, a $60 \mathrm{~m}$ mast, additional C-band antenna, and improved tracking and navigation devices were added (Fig. 1). A second X-band antenna was also added by the German Space Agency, and collected higher resolution topographic measurements in strips nested within the full, C-band coverage (Werner et al., 2000).

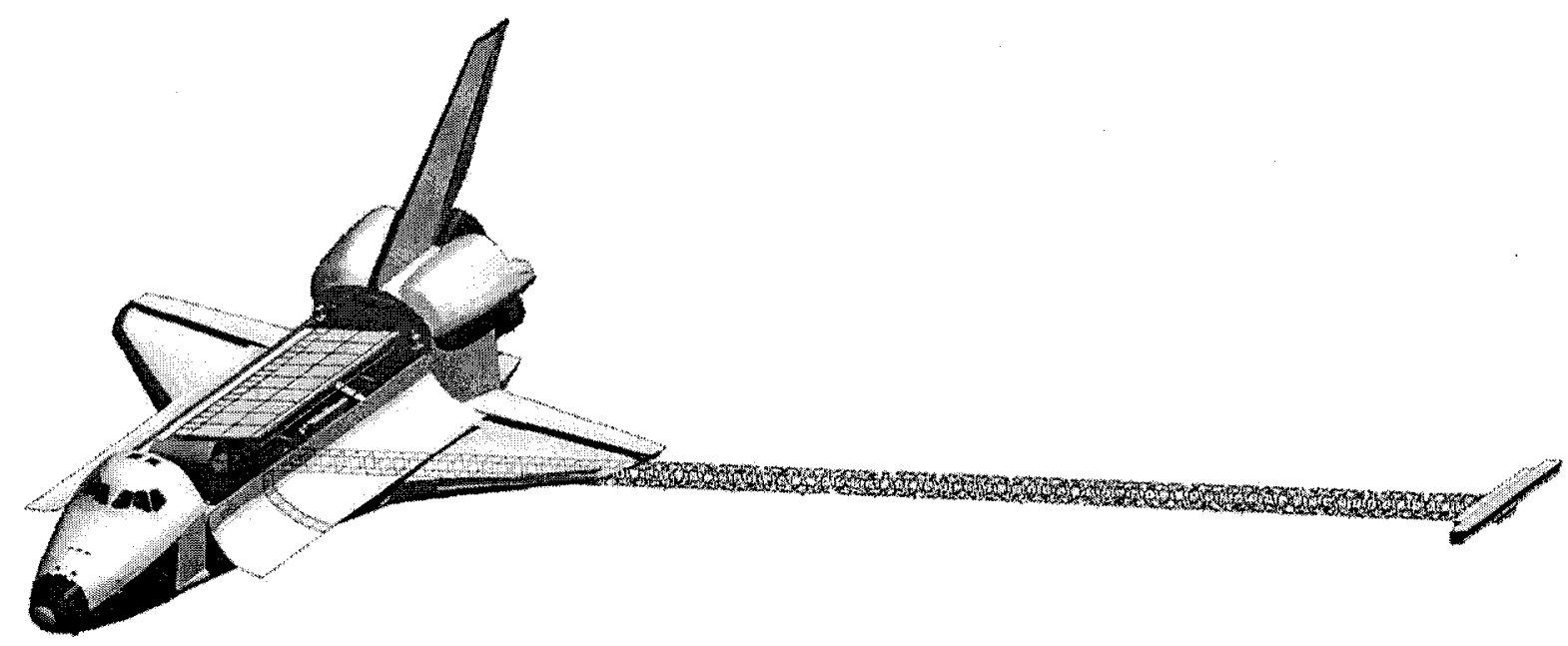

Figure 1. The SRTM payload in the Space Shuttle. The main antenna is seen in the payload bay and the outboard antennas are at the end of a $60 \mathrm{~m}$ mast. 
The major part of the SRTM hardware resided in the payload bay of the Space Shuttle (Fig. 2). This included the main structure, supporting the $L, C$, and $\mathrm{X}$-band antenna panels, the mast canister, and the Attitude and Orbit Determination Avionics (AODA). Due to weight limitations, the L-band panels were removed. The C-band system was operated in a 4-beam
scanSAR mode to acquire a $225 \mathrm{~km}$ swath, allowing complete coverage in 10 days, with a small overlap at the equator. Owing to the nature of the original SIRC/X-SAR digital data handling system, the scanSAR system was operated in a dual-polarization mode: two beams were $\mathrm{HH}$ polarization and two were VV.

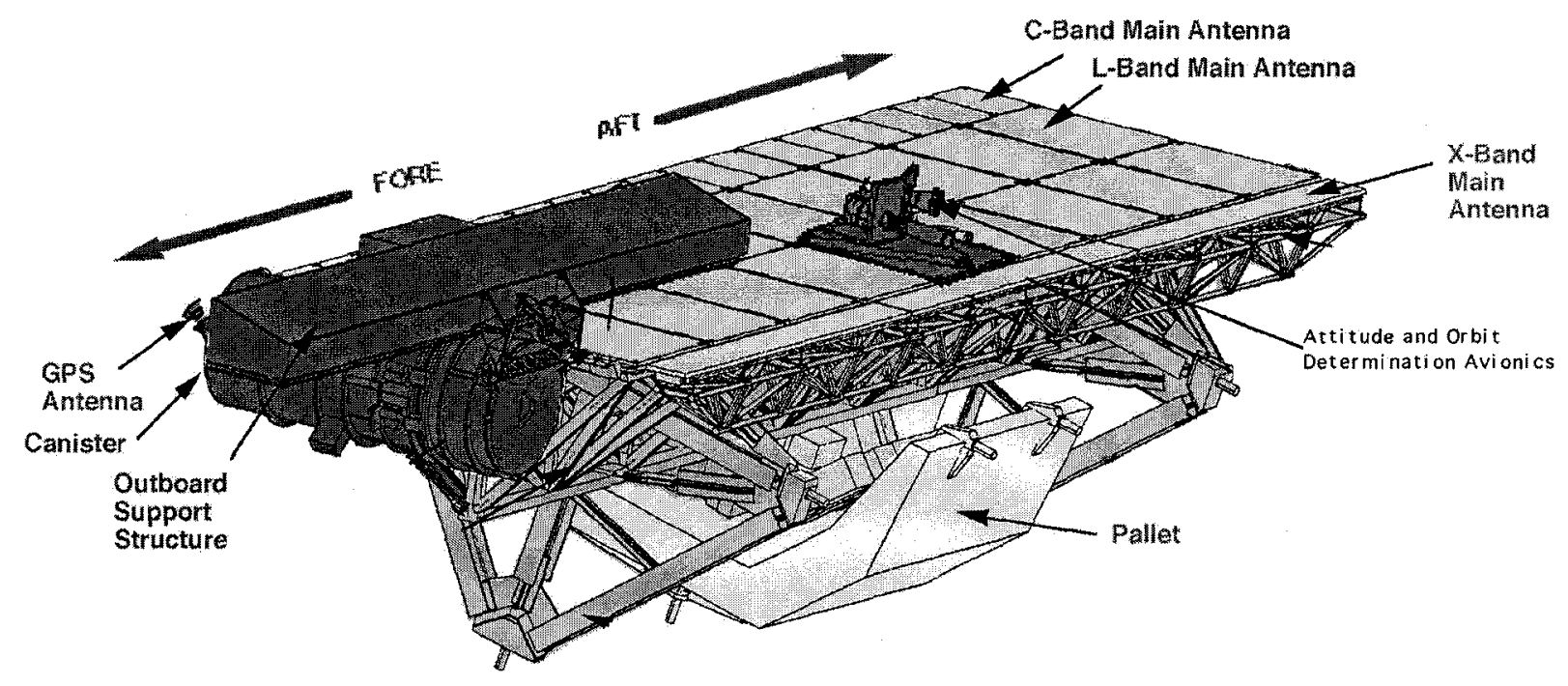

Figure 2. A detailed view of the SRTM hardware in the Space Shuttle payload bay. The $60 \mathrm{~m}$ mast is in its stowed configuration; the outboard antennas are folded back on top of the main antenna.

The $60 \mathrm{~m}$ mast was produced by AEC-Able Engineering, based on designs for the International Space Station. It consisted of carbon-fiber longerons forming cubes, or bays, with titanium wires under tension as cross-braces. There were 87 bays, each about $70 \times 80 \mathrm{~cm}$ making up the full $60 \mathrm{~m}$ length. The mast was stored as a collapsed spiral in a canister $2.9 \mathrm{~m}$ in length. When deployed, the Shuttle with the mast was the largest structure ever flown in space.

An important addition to the original SIR-C/X-SAR hardware was the Attitude and Orbit Determination Avionics (AODA; Duren et al., 1998). This system was required to obtain data on the length and orientation of the mast and the location and orientation of the Shuttle in earth-centered inertial coordinates. These factors are critical to the creation of an accurate digital topographic map automatically without the necessity of ground control points. AODA occupied the place of one of the L-band panels on the face of the main antenna (Fig. 2). It consisted of an Astro Target Tracker, Electronic Distance Meters, Star Tracker, GPS receivers, and an Inertial Reference Unit. The Astro Target Tracker was a modified star tracker with new optics designed to allow it to track a set of LEDs mounted on the outboard antenna structure, recording data on the motions of the outboard antenna relative to the main antenna. The Electronic Distance Meters were off the shelf Leica surveying instruments modified for the space environment and set up to measure the length of the mast to better than $3 \mathrm{~mm}$. The GPS receivers were built at JPL to measure the location of the Shuttle at $1 \mathrm{~m}$ accuracy using antennas on the outboard antenna structure (Fig. 2). AODA data were recorded continuously and stored on the Shuttle as well as sent to the ground for incorporation into the processing stream of the interferometric data.

Another important addition to the SRTM hardware was the presence of several laptop computers on the aft flight deck of the Shuttle. These monitored and archived AODA data and controlled the Payload High Rate Recorders. AODA data were sent to one set of laptops so that the Shuttle crew could monitor mast motions. This also aided in the initial alignment of the inboard and outboard antennas by the astronaut crew. The recorders were the same as flew on the SIR-C/XSAR missions, but due to a desire to more efficiently pack data onto a limited number of tapes and the fact that some data takes were longer than a single tape, a more sophisticated controller was needed. The laptop controlling the recorders sensed the approaching end of a tape, started the next recorder to produce overlapped data, and then handed over to the second recorder.

As the full C-band data rate of $180 \mathrm{Mb} / \mathrm{s}$ was about 4 times that of the Shuttle downlink capacity through the Tracking and Data Relay Satellite System, full interferometric data could not be downlinked in real time. However, during the mission some data were played back from tape at one-quarter speed and processed overnight at JPL and the German Space Agency. This provided an end-to-end check of the entire system. 
SRTM launched aboard Space Shuttle Endeavour on February 11, 2000 and had a nearly flawless 11 day flight, landing on February 22 with over 10 terabytes of data on over 300 tapes. Upon landing, the flight data tapes were transferred to a secure area at Kennedy Space Center, copied, and delivered to JPL for processing. After a checkout and calibration period, full data processing will begin in spring 2001 and take approximately 1 year.

The ground data processing system is broken into 3 parts: Interferometric processor, which converts the raw radar data into strip height maps and radar image strips; Mosaic processor, which takes the myriad of strips from all over the world and compiles a mosaic of the height and image data a continent at a time, allowing block adjustments on that scale; and the Verification system, which tests the mosaics for quality, producing an accuracy map (Rosen et al., 2000). Mosaics will be delivered to NIMA, where some validation of the data set will be done. The data will also be delivered to the civilian archive at the U.S Geological Survey's EROS Data Center. Current agreements call for the full resolution data covering the United States to be publicly available, however for areas outside the U.S., the data will be averaged to 90 $\mathrm{m}$ pixels for public release. NASA and NIMA will review requests for scientific use of the full resolution data for areas outside the U.S. on a case by case basis.

An extensive program for calibration and verification of the SRTM data will be undertaken. The calibration of the interferometer will allow fully automatic processing of the data to absolute Digital Elevation Models (DEM). In addition to the measurements made by AODA, radar path delays were monitored by a phaselocked optically coupled calibration tone injected at the input to the receiver chains. These systems provided accurate relative calibration over short (less than the orbit period) time scales. Longer period errors in the mosaics will be evaluated with a globally distributed set of small, high-resolution DEMs, ground control points, and kinematic GPS surveys. Absolute calibration will be carried out through measurements at two ground control sites as well as of the ocean surface before and after every coast crossing, along with a few long deep-ocean passes.

\section{Acknowledgements}

Work performed under contract to NASA. More information about the Shuttle Radar Topography Mission can be found at: http://www.jpl.nasa.gov/srtm/

\section{References}

Duren, R., E. Wong, B. Breckenridge, S. Shaffer, C. Duncan, E. Tubbs, and P. Salomon, 1998, Metrology, attitude, and orbit determination for spaceborne interferometric synthetic aperture radar, Proceedings of SPIE, Acquisition, Tracking, and Pointing XII, v. 3365, p.51-60.

Evans, D.L., J.J. Plaut, E.R. Stofan, 1997, Overview of the Spaceborne Imaging Radar-C/X-Band SyntheticAperture Radar (SIR-C/X-SAR) Missions, Rem. Sens. Env., v. 59, p. 135-140.

Madsen, S.N., H.A. Zebker, 1998, Imaging Radar Interferometry, ch. 6 in Henderson, F.M., A.J. Lewis, ed., 1998, Principles and Applications of Imaging Radar, Manual of Remote Sensing, v. 2, Wiley, NY, $866 \mathrm{pp}$.

Rosen, P., S. Hensley, J. Martin and E. Rodriguez, 2000, First Results from SRTM: The Beginning of the World's Digital Topography, abs., IGARSS 2000, Honolulu.

Werner, M., D. Hounam and W. Keydel, 2000, XSAR as Part of SRTM, abs., IGARSS 2000, Honolulu. 